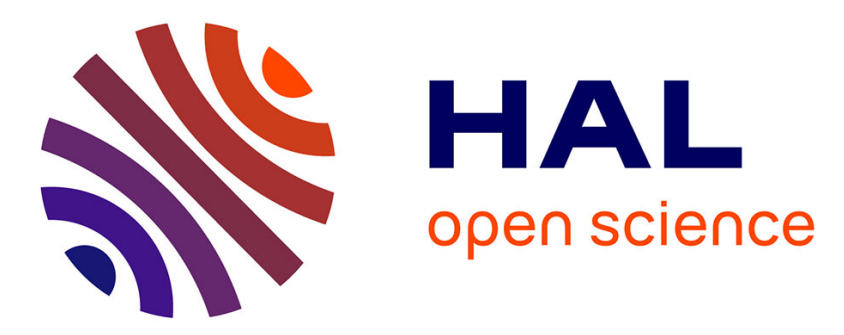

\title{
THE MICROSTRUCTURAL EVOLUTION DURING DEFORMATION UNDER SEVERAL STRAIN RATES IN A COMMERCIAL 5182 ALUMINIUM ALLOY
}

K. Higashi, T. Mukai, K. Kaizu, S. Tsuchida, S. Tanimura

\section{- To cite this version:}

K. Higashi, T. Mukai, K. Kaizu, S. Tsuchida, S. Tanimura. THE MICROSTRUCTURAL EVOLUTION DURING DEFORMATION UNDER SEVERAL STRAIN RATES IN A COMMERCIAL 5182 ALUMINIUM ALLOY. Journal de Physique IV Proceedings, 1991, 01 (C3), pp.C3-347-C3-352. 10.1051/jp4:1991350 . jpa-00250494

\section{HAL Id: jpa-00250494 https://hal.science/jpa-00250494}

Submitted on 1 Jan 1991

HAL is a multi-disciplinary open access archive for the deposit and dissemination of scientific research documents, whether they are published or not. The documents may come from teaching and research institutions in France or abroad, or from public or private research centers.
L'archive ouverte pluridisciplinaire HAL, est destinée au dépôt et à la diffusion de documents scientifiques de niveau recherche, publiés ou non, émanant des établissements d'enseignement et de recherche français ou étrangers, des laboratoires publics ou privés. 
THE MICROSTRUCTURAL EVOLUTION DURING DEFORMATION UNDER SEVERAL STRAIN RATES IN A COMMERCIAL 5182 ALUMINIUM ALLOY

\author{
K. HIGASHI*, T. MUKAI*, K. KAIZU* , S. TSUCHIDA* ${ }^{*}$ and \\ S. TANIMURA * \\ "Department of Mechanical Engineering, College of engineeiring. \\ University of Osaka Prefecture, Mozu-umemachi, Sakai, Osaka \\ 591, Japan \\ * Technical Research Laboratories, Sumitomo Light Metal \\ Industries, Ltd, Nagoya, Aichi, Japan
}

La contrainte d'écoulement d'un alliage d'aluminium 5182 a été déterminée en fonction de la vitesse de déformation entre $10^{-3} \mathrm{~s}^{-1}$ et $4.10^{3} \mathrm{~s}^{-1}$ à température ambiante. L'alliage d'aluminium montre une sensibilité négative à la vitesse de déformation dans un domaine où celle-ci est inférieure à $10^{2}$ $\mathrm{s}^{-1}$, la contrainte d'écoulement maximum décrô̂t quand la vitesse de déformation augmente. Cette tendance est aussi observée pour d'autres alliages d'aluminium au magnésium tels le 3004 et le 7N01. On déduit de l'observation par M.E.T., que la diminution de la densité de dislocations résultant de l'arrangement en réseau des bandes de déformation de dislocation conduit à la contrainte minimum pour la déformation où la sensibilité négative à la vitesse de déformation est observée.

\begin{abstract}
The flow stress of a commercial 5182 aluminum alloy has been investigated as a function of strain rates in the range from $1 \times 10^{-3}$ to $4 \times 10^{3} \mathrm{~s}^{-1}$ at room temperature. The $\mathbf{5 1 8 2}$ alloy exhibited the negative strain rate sensitivity of flow stress in a strain rate range below $10^{2} \mathrm{~s}^{-1}$, of which the maximum flow stress decreased with increasing strain rate. This tend in flow stress with strain rates was observed for other commercial aluminium alloys which include magnesium atoms in solute such as the 3004 and $7 \mathrm{NO} 1$ alloys. It seems that the microstructual evolution during deformation has occurred in these alloys. The incremental strain rate tests revealed that the true strain rate sensitivity is positive under the same structure of alloys, and there appear to be the negative strain rate sensitivity corresponding to the microstructural evolution after some deformations. From the observation by transmission electron microscopy, the decreasing of dislocation densities resulting from the arrangement of the network-like deformation bands by disiocations with straining. lead to the lower stresses at the strains where the negative strain rate sensitivity is observed.
\end{abstract}

\title{
1-INTRODUCTION
}

It has been reported that the negative strain rate sensitivity of the flow stress for some alloys such as mild steels[1] and Al-Mg alloys[2] is caused by the strain aging. Recently, some commercial aluminum alloys, which contained magnesium atoms in solute, exhibited the negative strain rate sensitivity of the maximum flow stress in the strain rate range below $10^{2} \mathrm{~s}^{-1}$ at room temperature[3]. On stress-strain rate curves of these alloys, the deformation histories for each strain rate were not same even if the tests were carried out in constant strain rate. Therefore, the strain rate sensitivity seems to be undetermined apparently under non-constant structure of alloys. The jump tests, incremental strain rate tests, should be done to estimate the true strain rate sensitivity for any strains at each strain rate. 
The purpose of this work is to estimate the true strain rate sensitivities of the 5182 alloy by the incremental strain rate tests, and is to investigate the microstructural evolution during deformation under several strain rates by the observations of transmission electron microscopy.

\section{2-EXPERIMENTAL PROCEDURE}

The chemical composition of an commercial $5182 \mathrm{Al}-\mathrm{Mg}$ alloy used in this study is given as an $\mathrm{Al}-4.52 w t \% \mathrm{Mg}-0.35 \mathrm{wt} \% \mathrm{Mn}-0.25 w \mathrm{t} \% \mathrm{Fe}-0.10 \mathrm{wt} \% \mathrm{Si}$. Tensile specimens, machined from hot rolled plates, had their tensile axes normal to the rolling direction. The gauge length of the specimen is $4.5 \mathrm{~mm}$, and the diameter is $3 \mathrm{~mm}$. All specimens were heated to $643 \mathrm{~K}$ with a heating rate of $47 \mathrm{~K} /$ hour and then annealed for $2 \mathrm{hrs}$. in air. The typical microstructure is shown in Fig. 1. There are many second phase particles in the matrix. These particles are of the manganese or silicon compound. The former are a little smaller than the latter. These particles are distributed along the rolling direction. The size of these particles are of the sub-micrometer order with the mean distance of about $1 \mu \mathrm{m}$.
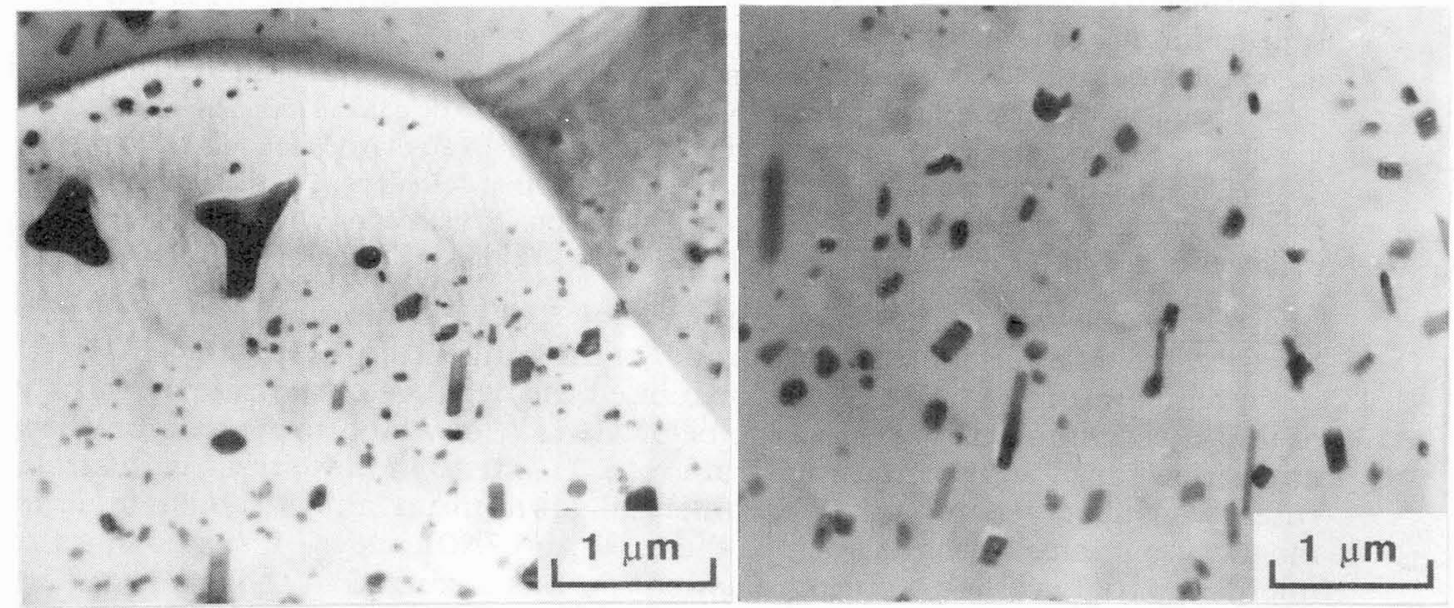

Fig.1 The typical microstructure for 5182 alloy after annealing at $643 \mathrm{~K}$ for $2 \mathrm{hrs}$.

For the tension tests, these specimens were tested at strain rates between $1 \times 10^{-3}$ to $4 \times 10^{3} \mathrm{~s}^{-1}$ at room temperature. Low strain rate tensile tests $\left(1 \times 10^{-3} \sim 1 \times 10^{-1} \mathrm{~s}^{-1}\right)$ were performed with an instron machine, and intermediate strain rate tensile tests $\left(1 \times 10^{-1} \sim 3 \times 10^{2} \mathrm{~s}^{-1}\right)$ were performed with the hydraulic tensile testing machine, and the dynamic tensile tests $\left(4 \times 10^{2} \sim 4 \times 10^{3} \mathrm{~s}^{-1}\right)$ were performed using a split Hopkinson pressure bar system which incorporates a specific attachment. The incremental strain rate tests were performed by the hydraulic tensile testing machine. This machine has a valve corresponding proportionally to given voltage. Therefore, using a computer with a controlling voltage pattern, the constant strain rate tests or the incremental strain rate tests can be performed. The transmission electron microscopy has been used for the microstructural observation.

\section{3-RESULTS AND DISCUSSIONS}

The typical stress-strain curves of the $5182 \mathrm{Al}-\mathrm{Mg}$ alloy are shown in Fig.2 for several strain rates. The higher the strain rates are, the higher the flow stresses at an early stage of deformation $(\varepsilon<0.05)$ become for all strain rates. However, the flow stresses 
beyond this strain at both intermediate strain rates of $5 \times 10^{-1}$ and $10 \mathrm{~s}^{-1}$ are lower than those in both strain rates below and over this intermediate strain rates. The serrations have been observed on the load and displacement curves in the strain rate range below $10^{-2} \mathrm{~s}^{-1}$. Then the changes of flow stress for true strain levels, $\varepsilon=0.002,0.05,0.1, \ldots 0.25$ are shown in Fig.3 as a function of the strain rate. In the low and intermediate strain rate range between $10^{-3}$ and $100 \mathrm{~s}^{-1}$, the values of flow stress at yield point $(\varepsilon=0.002)$ is a weak function of strain rate. As strain rate increases the flow stress increases with strain rate. The values of flow stress at yield point increase rapidly with increasing

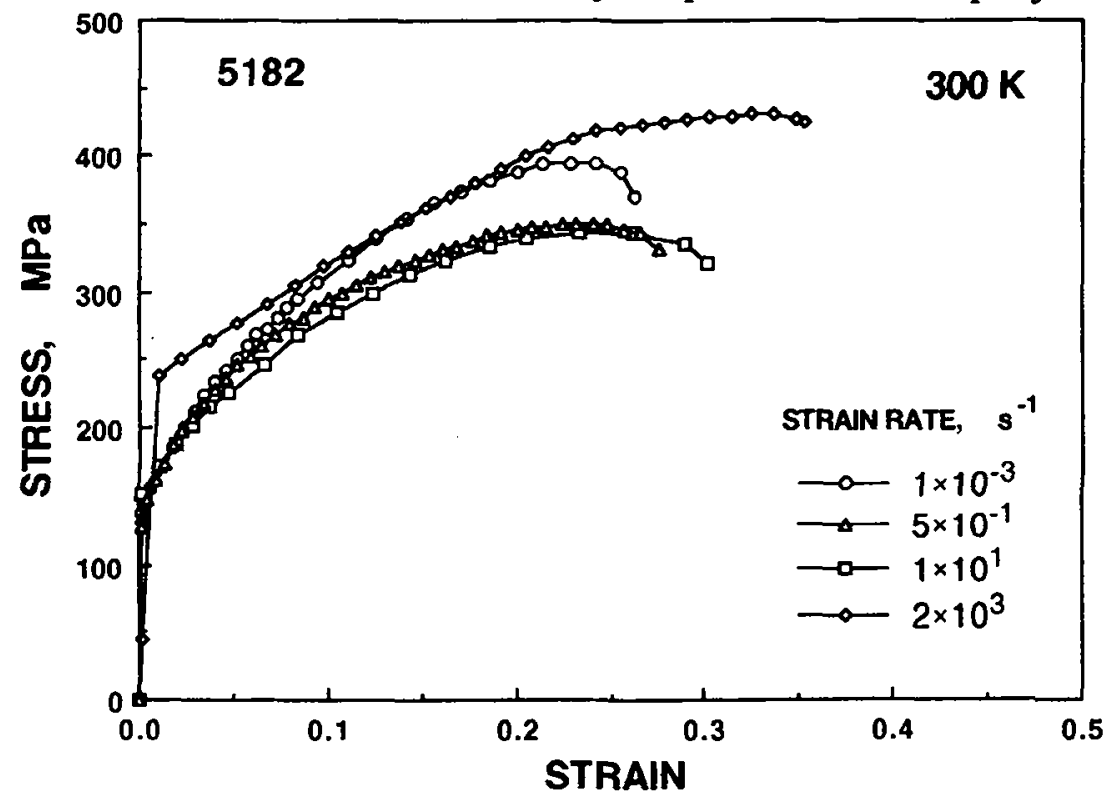

Fig.2 Typical stress-strain curves for 5182 alloy

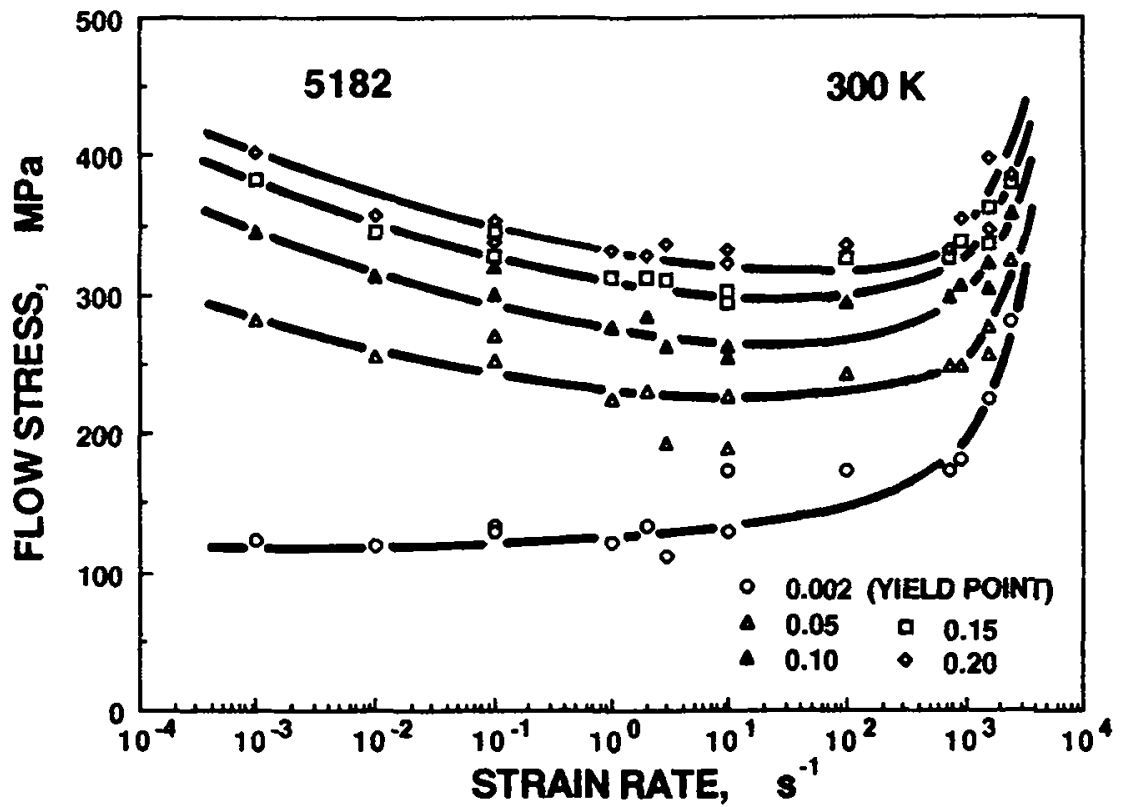

Fig.3 The changes of flow stress as a function of the strain rate ( for true strain levels, $\varepsilon=0.002,0.05,0.1, \ldots 0.25$ ) 
strain rate in the high strain rate range over $100 \mathrm{~s}^{-1}$. On the other hand, the values of flow stress at given true strain of more than 0.05 is a different function of strain rate. As strain rate increases the flow stress decreases with strain rate in the low and intermediate strain rate range. The experimental results show the negative strain rate sensitivity apparently at the strain of more than 0.05 .

The typical stress-strain curve obtained by the rapid strain rate change test is shown in Fig.4. The curve (a) was obtained from the test in the constant strain rate of 0.5 $\mathrm{s}^{-1}$ and the curve (b) was done from the incremental strain rate test, where the rate changing point is $e=0.04$, and the first strain rate is $0.5 \mathrm{~s}^{1}$ and the second strain rate is $10 \mathrm{~s}^{-1}$. The structure is same at the rate changing point, therefore the true strain rate sensitivity exponent is calculated at 0.02 . It is important to note that the true strain rate sensitivity should not be negative but positive. However there appear to be negative strain rate sensitivity later as the deformation is still progressing.

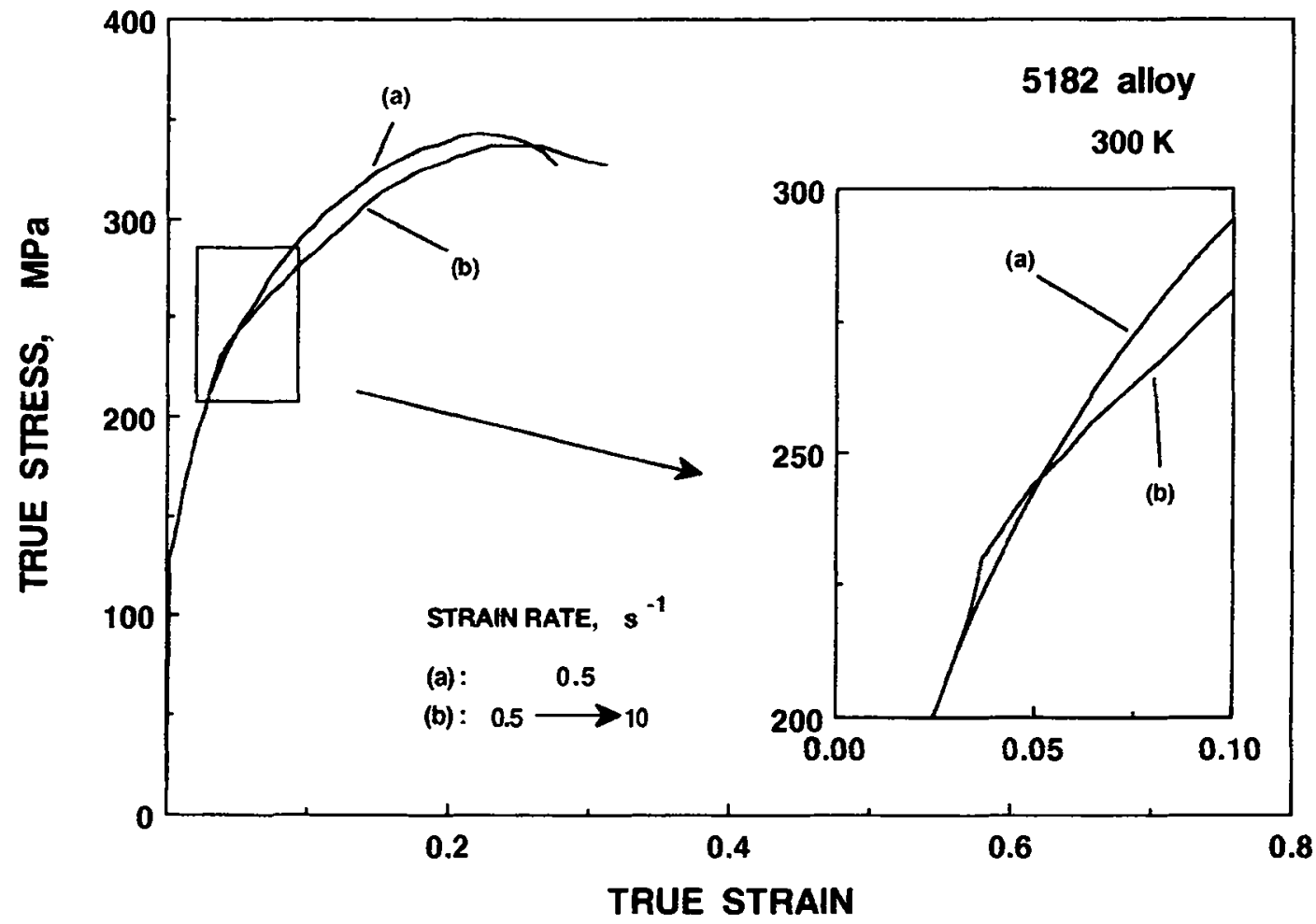

Fig.4 The typical stress-strain curve obtained by the rapid strain rate change test

Fig.5(a) and (b) show the typical microstructure at fixed strain of 0.10 deformed by the constant strain rate test at the strain rate of $0.5 \mathrm{~s}^{-1}$ and the incremental strain rate test at the first strain rate of $0.5 \mathrm{~s}^{-1}$ to the second strain rate of $10 \mathrm{~s}^{-1}$. The formation of the network-like deformation bands was observed in both tests. The particles in the sub-micrometer size are at the cross of these network-like deformation bands, which consisted of many tangled dislocations. The intervals of these micro deformation bands correspond to the distance of the particles. Therefore, the particles play an important role in forming the network-like deformation bands. Dislocation density observed in 
Fig.5(b) seems to be lower than that in Fig.5(a). This trend of the lower density in dislocation corresponds to the decreasing of the stress level as observed in Fig.4.

Fig.6(a) and (b) show the same microstructure of Fig.5 with a higher magnification respectively. The formation of dislocations can be observed; many dislocations cross each other or are pinned by the particles, also many dislocation loops can be observed. Dislocation density in Fig.6(a) also is higher than that in Fig.6(b).
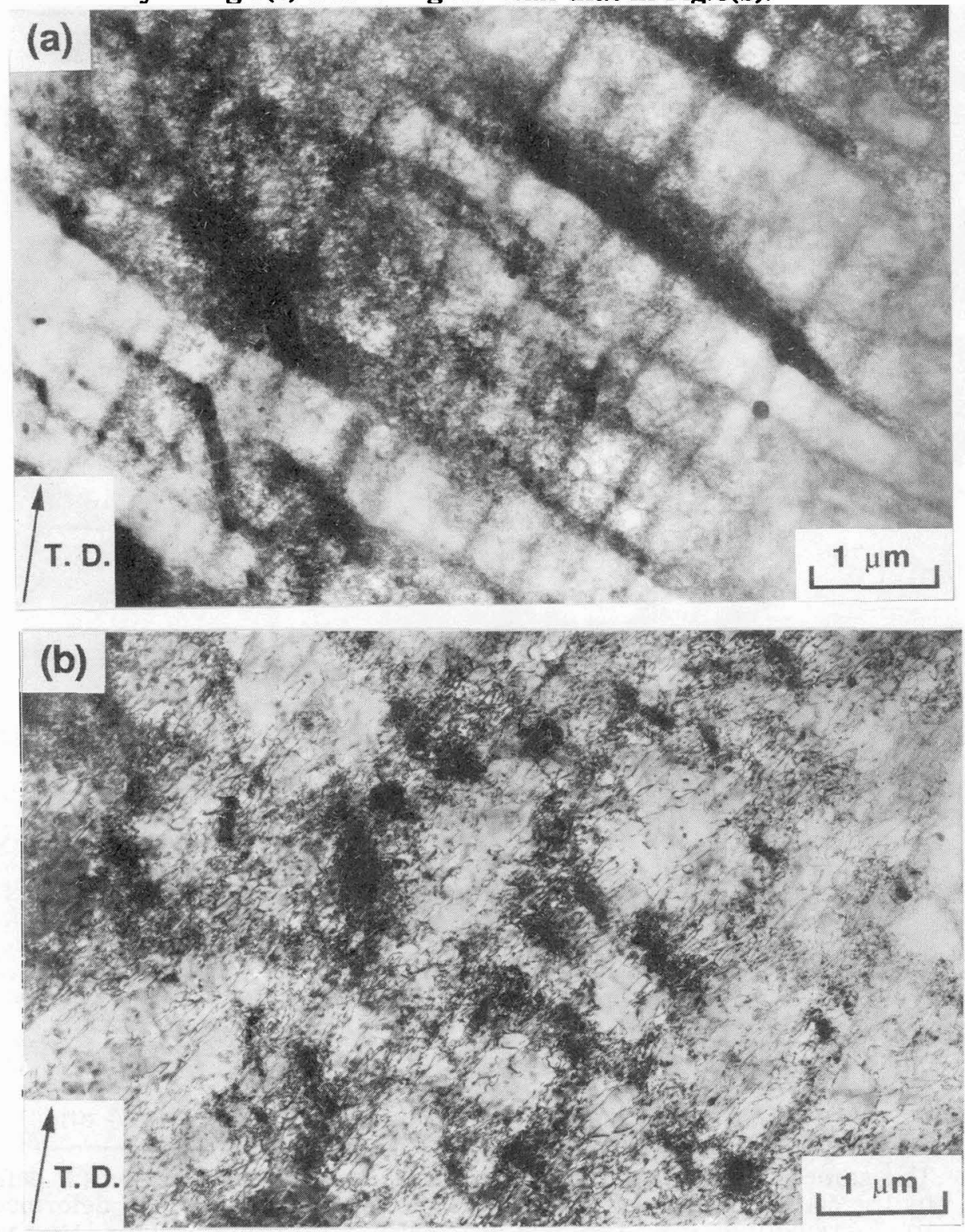

Fig. 5 The typical microstructure at fixed strain of $0.10 \quad$ (a) deformed by the constant strain rate test at the strain rate of $0.5 \mathrm{~s}^{-1}$ (b)deformed by the incremental strain rate test at the first strain rate of $0.5 \mathrm{~s}^{-1}$ to the second 4-SUMMARY strain rate of $10 \mathrm{~s}^{-1}$

Experimental results of the $\mathbf{5 1 8 2}$ aluminum alloy exhibited that the negative strain rate sensitivity in a strain rate range below $10^{2} \mathrm{~s}^{-1}$ is only an apparent value under different conditions of straining histories and the true strain rate sensitivity of flow stress is 
positive under the same structure of alloys. The decreasing of dislocation densities resulting from the arrangement of the network-like deformation bands by dislocations with straining, lead to the lower stresses at the strains where the negative strain rate sensitivity is observed.

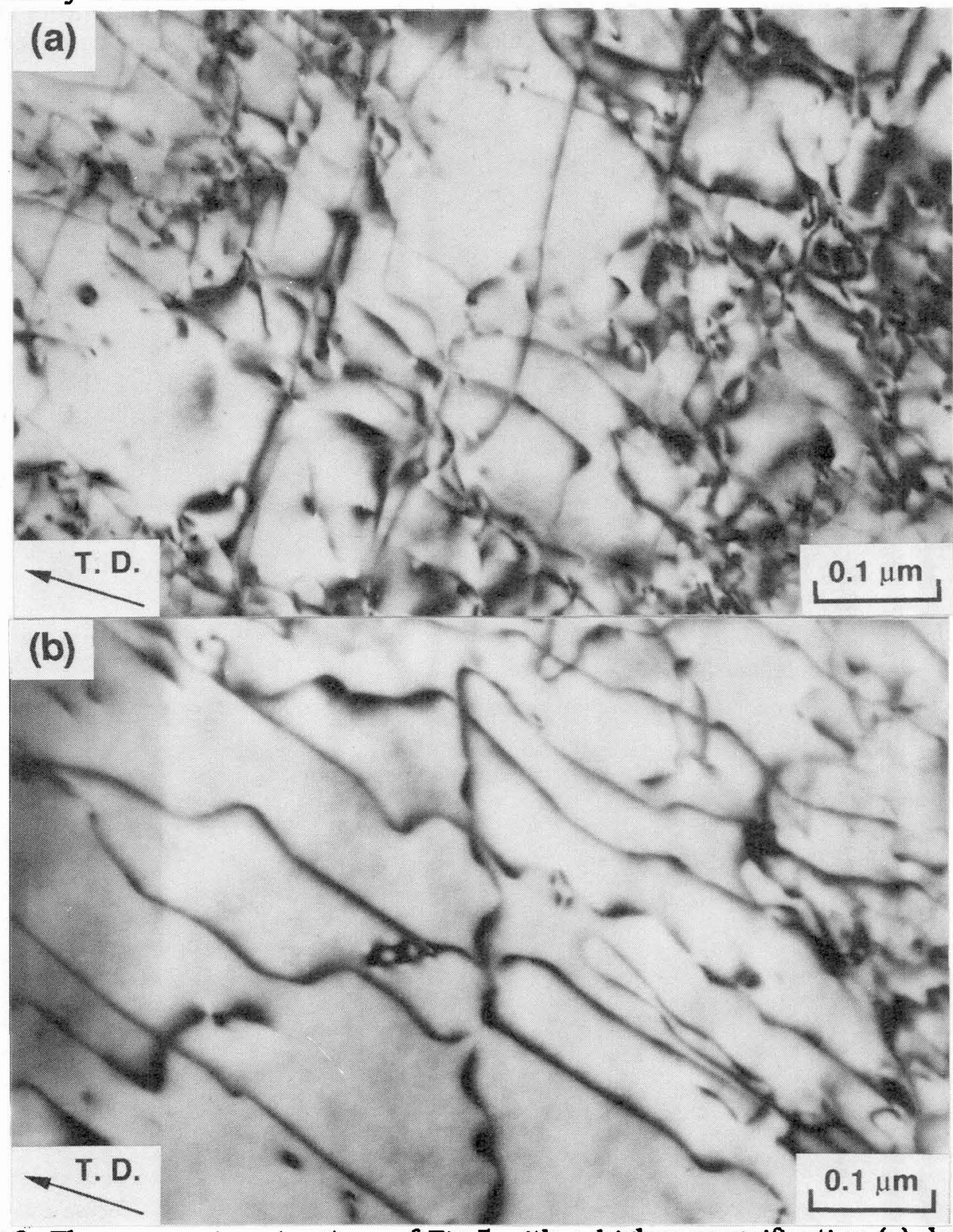

Fig.6 The same microstructure of Fig.5 with a higher magnification (a) deformed by the constant strain rate test at the strain rate of $0.5 \mathrm{~s}^{-1}$ (b) deformed by the incremental strain rate test at the first strain rate of $0.5 \mathrm{~s}^{-1}$ to the second strain rate of $10 \mathrm{~s}^{-1}$

\section{REFERENCES}

/1/ Nadai, A., "THEORY OF FLOW AND FRACTURE OF SOLIDS", VOLUME ONE, MCGRAW-HILL Book COMPANY, Inc. (1950) 313-316.

/2/ Korbel. A., and Dybiec. H., Acta Metallurgica, 29 (1980) 89-93.

/3/ Higashi, K., Mukai, T., Kaizu, K., Tsuchida, S., and Tanimura. S., In this proceedings. 